\title{
Analysis and Monitoring Technology of Upper Seam Mining in Multiunderlayer Goaf
}

\author{
Han Liang $(\mathbb{D}$, Pengfei Li, and Chen Cao \\ College of Mining Engineering, Liaoning Technical University, Fuxin 123000, China \\ Correspondence should be addressed to Han Liang; 18641822228@163.com
}

Received 14 May 2021; Accepted 15 July 2021; Published 22 July 2021

Academic Editor: Shangtong Yang

Copyright $(2021$ Han Liang et al. This is an open access article distributed under the Creative Commons Attribution License, which permits unrestricted use, distribution, and reproduction in any medium, provided the original work is properly cited.

Based on the background of close coal seam mining in the Qianjiaying coal mine, Tangshan, China, the feasibility of the upper seam mining in complex underlaying goaf is analysed using the roof caving analysis and numerical method. The deformation of the mining seam and roadways is monitored and analysed by field measurement and 3D laser scanning. The deformation characteristics of \#5 seam after mining 1378P, 2071P, 2072P, and 2091P working panels with a depth of 39-54 m below the \#5 seam are analysed using roof caving analysis and numerical method. Results show that the maximum deformation of \#5 seam in the superimposed area of the lower goafs reaches $2.5 \mathrm{~m}$ and the maximum deformation in the single coal goaf is $1.5 \mathrm{~m}$. The maximum seam inclination is $1.9^{\circ}$. The subsidence of the floor of $1359 \mathrm{P}$ roadways is obtained by field measurement, and the result is consistent with numerical calculation. ZEB-HORIZON 3D laser scanner was used to measure and model the roadway deformation. Based on the analysis of multiple scanning data, the deformation of the 1359P roadways was obtained. Results show that the deformation of the surrounding rock of the roadway is not great, the maximum displacement of the roof fall is $30 \mathrm{~mm}$, and the maximum rib convergence is $25 \mathrm{~mm}$. It can be concluded that the \#5 seam can be recovered in this complex underlying lower seams' mining condition.

\section{Introduction}

Close multiseams mining refers to the coal seams with mutual influence. As excavation has greater impact on the roof than the floor, the downward mining method is often used to reduce the influence on adjacent seams [1]. In practice, due to uncertainty of geological exploration or unsatisfied mining conditions, the lower seam may be mined firstly, namely, upward mining. Upward mining faces the challenges of upper seam and surrounding rock subsidence, fracturing and bending, gas imitation, and stress concentration directly above lower seam pillar [2-7]. Considering the timed effect of lower goaf compaction, the situation of upward mining for close multiple coal seams is complex; thus, it is often studied case-by-case in practice.

The lower seams' mining causes upper seam movements and ground stress unloading, which introduce fractures influencing the stability of surrounding rock of upper seam [8-15]. The research of the upward mining method mainly focuses on the overburden damage analysis caused by lower seam mining and the deformation monitoring and strata control technology while upper seam mining. The former addresses the feasibility of upper seam mining. For example, based on the statistics of more than 200 upward mining cases, Wang and Li [8] suggested that the feasibility of upward mining can be determined using three zones' discrimination and surrounding rock equilibrium methods. Han et al. [9] classified the extent of damnification of upper seam caused by lower seam mining and established the criterion for the upward mining of close seams using the multivariate regression analysis. Wang et al. [16] identified the overburden stress distribution and fracture field for upward mining. In a case study, Zhang et al. [17] found that the fracture in upper seam located above the caving zone was recovered after a certain period, indicating that the upper seam could be mined. Jiang et al. [18] obtained roof stress distribution using the continuous beam model under uniformly distributed load, which can be used to study the feasibility of upper seam mining above large goaf area. 
Another key of upward mining is strata deformation monitoring and related ground control technologies in upper seam development and excavation [19-23]. Suchowerska et al. [19] studied the vertical stress redistribution in close seam mining. Shao et al. [20] conducted simulation experiment study on the overlying rock fracture and stability of interlayer strata in upward mining, and result showed that the upper seam working face could pass through the fracture zone safely under proper support technique. Based on the theory of composite overburden structure, Huang et al. [24] considered the fracture zone inclined to the inner side of the goaf and proposed two schemes of upward mining, namely, the overlaying method and the staggering pillar method. Zhang [25] monitored the overburden movement during upward seam excavation, and the roof caving angle, overburden displacement, and large and small periodic weighting intervals were studied. Zhao et al. [26] calculated the range of upper seam influenced by lower seam mining in Qianjiaying and proposed a roadway reinforcing scheme for passing through lower seam pillars. Based on theoretical analysis and numerical calculation, Wang et al. [27] studied the upper seam floor subsidence upon lower seam open cut, and it showed that the working face was unstable while passing through the lower seam open cut, and special support should be implemented.

Qianjiaying colliery, located in Tanshan, China, is a typical close multiseams' coal mine. After mining out two lower seams, it is necessary to determine the possibility of upward mining [28]. In this paper, the influence of the lower seams' mining on the overlying strata is determined based on the roof caving analysis. Then, the subsidence and bending angles of the upper seam due to lower seams mining are calculated using numerical method, so as to provide a criterion for the feasibility of upward mining. After roadway development of the upper panel, the actual subsidence of the upper seam floor is measured based on elevation data. Before panel excavation, multiple 3D laser scanning was carried out in the roadways using the ZEB-HORIZON 3D laser scanner, and the deformation of the upper roadways beyond lower seam coal mass, goaf, roadway, and coal pillars was evaluated to provide a basis for monitoring and strata control in the excavation. This paper conducts a case study of upper seam mining over complex lower seam conditions using theoretical, numerical, and field monitoring methods, which provide a reference for feasibility judgement and premining confirmation of upward mining under similar geocondition.

1.1. Field Conditions. Qianjiaying coalmine is $17 \mathrm{~km}$ east of Tangshan, China, with a mining area of $42.6 \mathrm{~km}^{2}$. The minable coal includes $\# 5$, \#7, \#9, and \#12 seams with total recoverable coal $600 \mathrm{Mt}$ and annual production of around 6.0 Mt. The seams have medium thickness with composite overlaying strata; the bury depth is about $600-800 \mathrm{~m}$ underground. In situ stress measurements suggest that the major and medium principle stresses of the Qianjiaying coalmine are in horizontal direction, and the major principal stress to vertical stress ratio is around 1.6.
The seams are mainly formed by clarain and semiclarain. The average thickness of \#5, \#7, and \#9 seams is $1.4,3.6$, and $1.8 \mathrm{~m}$, respectively; their dipping angle is $1^{\circ}-10^{\circ}$. The distance between \#5 and \#7 seam is $39 \mathrm{~m}$ and is $54 \mathrm{~m}$ between $\# 5$ and 9 seam. The comprehensive stratigraphic column of related seams is shown in Figure 1. The mining method of \#7 and \#9 coal seams is full roof caving longwall mining.

Before mining of 1359 panel (shorten as 1359P hereafter) in \#5 seam, 1378P, 2071P, and 2072P in \#7 seam were mined out in 2006, 2009, and 2012, respectively; 2091P in \#9 seam was mined out in 2017. The layout of the related panels is shown in Figure 2.

The roadway and mining direction of $1359 \mathrm{P}$ is nearly vertical to lower seams. The roadway development and face retreat of $1359 \mathrm{P}$ need to cross 4 gobs and 2 pillars.

The aim of this study is to evaluate the excavation possibility of $1359 \mathrm{P}$. Before roadway excavation of $1359 \mathrm{P}$, the influence of lower seams' mining towards \#5 seam should be studied quantitively. During roadway excavation, in situ measurement and data analysis should be conducted to confirm the prediction result. Before panel retreat, the deformation behaviour of $1359 \mathrm{P}$ roadways over different underlaying strata conditions should be monitored and evaluated to guarantee a safe environment of working face retreat.

1.2. Overlaying Strata Caving Analysis. After panel excavation, the overlying strata form caving zone, fracture zone, and subsidence zone from the bottom to the top. For upward mining, if the upper panel is within the caving zone of lower seam gob, the seam and surrounding rock are seriously broken and cannot be driven or mined. If the upper panel is within the fracture zone, the roadway is unstable as the fracture cannot be restored for a long time, i.e., the upper seam cannot be mined. If the upper panel is beyond the middle section of the fracture zone or within the subsidence zone, the upper seam keeps certain integrity although there are a large number of fractures developed in the coal and surrounding rock. After a certain period of compaction, the strata can restore stability and the seam can be safely mined [29-33].

The height of each zone is related to geological condition and mining method, which are often evaluated using the semitheoretical and semiempirical method $[1,8]$. According to the geological characteristics of Qianjiaying (Figure 1), the height of one single coal seam caving zone can be calculated using the following equation:

$$
H_{m}=\frac{M-W}{(K-1) \cos \alpha} .
$$

And, the height of the fracture zone can be calculated using

$$
\begin{aligned}
& H_{1}=\frac{100 \sum M}{1.6 \sum M+3.6} \pm 5.6, \\
& H_{2}=\sqrt{\sum M}+10,
\end{aligned}
$$




\begin{tabular}{|c|c|c|}
\hline Stratum & Histogram & $\begin{array}{c}\text { Ave } \\
\text { thickness (m) }\end{array}$ \\
\hline Siltstone & \multirow{6}{*}{ 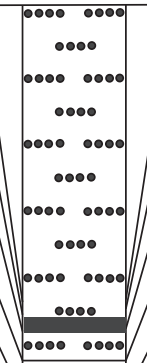 } & 34.6 \\
\hline Mudstone & & 0.2 \\
\hline 5 seam & & 1.4 \\
\hline Siltstone & & 3.0 \\
\hline Mudstone & & 4.1 \\
\hline Siltstone & & 3.6 \\
\hline 6 seam & $\begin{array}{|ll|}- & \\
0000 & 0000 \\
\end{array}$ & 0.3 \\
\hline Siltstone & $\ldots$ & 7.8 \\
\hline $\begin{array}{l}\text { Medium } \\
\text { sand }\end{array}$ & $\bullet$ & 8.5 \\
\hline Siltstone & 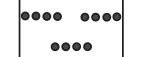 & 7.7 \\
\hline 7 seam & & 3.2 \\
\hline Siltstone & & 12.6 \\
\hline 9 seam & & 2.2 \\
\hline $\begin{array}{l}\text { Fine } \\
\text { sandstone }\end{array}$ & @ & 4.8 \\
\hline Mudstone & - & 9.0 \\
\hline Siltstone & 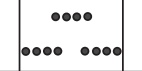 & 10.6 \\
\hline
\end{tabular}

FIgURE 1: Stratigraphic diagram of the studied area.

A

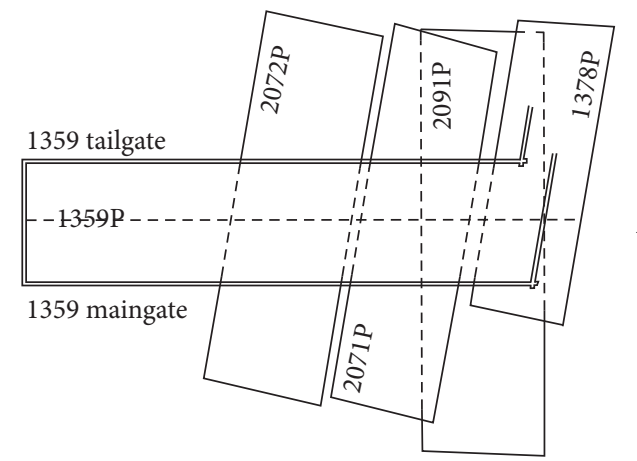

(a)
A

\begin{tabular}{|llll|}
\hline 5 seam & & & \\
\hline 7 seam & $2072 \mathrm{P}$ & 2071P & $1378 \mathrm{P}$ \\
\hline 9 seam & & & \\
\hline
\end{tabular}

A

Figure 2: Layout and cross-section view of the studied area.

where $M$ is the excavation thickness, $W$ is the roof subsidence, $K$ is the volumetric expansion coefficient of crushed rock, normally 1.1 1.4, and $\alpha$ is the seam dipping angle.

The mining height of $2071 \mathrm{P}$ is $3.4 \mathrm{~m}$ and the seam dipping angle is $8^{\circ}$. The roof fall is around $400 \mathrm{~mm}$ and the volumetric expansion coefficient of crushed rock is supposed to be 1.4. Then, the height of the caving zone can be estimated as $7.57 \mathrm{~m}$; the height of the fracture zone can be calculated as $32.0-43.2 \mathrm{~m}$ and $46.9 \mathrm{~m}$ based on equation (2) or (3), respectively. Based on safety consideration, the height of the fracture zone of $2071 \mathrm{P}$ can be estimated as $46.9 \mathrm{~m}$. The heights of the caving zone and the fracture zone of each lower seam panel can be calculated in a similar manner, and the result is summarized in Table 1.

The average distance between $\# 5$ and $\# 7$ seam is $39 \mathrm{~m}$, i.e., $1359 \mathrm{P}$ is located in the upper position of fracture zone of \#7 seam gob. Accordingly, \#7 seam gob has less influence on the deformation of $\# 5$ seam. The distance between $\# 5$ and \#7 seam is $54 \mathrm{~m}$, so \#5 seam is within the subsidence zone of \#9 gob. The deformation of \#5 seam due to \#9 seam mining is small. The gob of 2091P overlaps with $1378 \mathrm{P}$ and 2071P gobs, and the deformation of $\# 5$ seam over this area is expected large. 
TABLE 1: The height (in meters) of the caving zone and the fracture zone of related lower panels.

\begin{tabular}{lcccc}
\hline & $2071 \mathrm{P}$ & $2072 \mathrm{P}$ & $1378 \mathrm{P}$ & \\
\hline Caving zone $(\mathrm{m})$ & 7.57 & 8.08 & 7.71 & \\
Fracture zone $(\mathrm{m})$ & 46.9 & 48.0 & 47.3 & 3.03 \\
\hline
\end{tabular}

1.3. Numerical Calculation. To quantify the deformation of \#5 seam induced by lower seams' mining, a FLAC 3D calculation model is constructed to calculate the subsidence consequence of \#5 seam due to lower seams' mining. The model size is $1223(\mathrm{~L}) \times 566(\mathrm{~W}) \times 114(\mathrm{H}) \mathrm{m}$ using a total of 1193600 elements, as shown in Figure 3.

The mechanical properties of the surrounding rock used in the model are shown in Table 2.

The calculation procedure followed the consequence of lower seam mining [34]. After 2071P is mined out, the deformation nephogram and numerical simulation of \#5 seam floor are shown in Figure 4. It shows that the subsidence of the middle sections of $2071 \mathrm{P}$ gob and $1378 \mathrm{P}$ gob is large, up to $1.22 \mathrm{~m}$, and gradually decrease towards mining boundary.

Figure 5 shows side view of vertical displacement of A-A cross section. The maximum subsidence is $3.1 \mathrm{~m}$, occurs at the \#7 seam roof, and gradually decreases upwards. The subsidence of \#5 seam floor is around $1.0-1.2 \mathrm{~m}$.

After all lower panels are mined out, the subsidence of \#5 seam floor is shown in Figure 6. It shows that, after excavation of \#7 and \#9 seams, the subsidence of \#5 seam floor over the gob areas is $1.0-2.5 \mathrm{~m}$, and the maximum deformation is on the overlapped area of $1378 \mathrm{P}$ gob and $2091 \mathrm{P}$ gob.

Figure 7 shows the subsidence of middle axial of 1359P (A-A in Figure 2). The maximum subsidence is $2.5 \mathrm{~m}$. The bending angle of the seam is calculated based on the subsidence geometry. It shows that the maximum bending angle is around $1.9^{\circ}$, according to studies related to deformational behaviour of coal mass [31, 35-37], and it suggests that the rock integrity of $1359 \mathrm{P}$ is favourable.

1.4. Field Measurement. The results of roof caving analysis and numerical calculation suggest that the $1359 \mathrm{P}$ is minable. After roadway development, the subsidence of \#5 seam should be measured to confirm pre-excavation prediction. In reality, due to the coal seam pinch out, the final length of the tailgate is $544.6 \mathrm{~m}$, i.e., $112 \mathrm{~m}$ beyond the $2072 \mathrm{P}$ goaf boundary. The final length of the maingate is $583.9 \mathrm{~m}$ and $76 \mathrm{~m}$ beyond the 2072P goaf boundary.

Based on the survey, the subsidence of the 1359P roadway floor is analysed. The roadways of $1359 \mathrm{P}$ are developed along the floor. The elevation at the corner of tailgate and open cut is $-618.37 \mathrm{~m}$, and the elevation at the corner of the maingate and open cut is $-611.9 \mathrm{~m}$. The subsidence contours of the roadway floor are obtained by the comparison of the elevation data before and after lower seams' excavation, as shown in Figures 8 and 9. The dashed line is the floor elevation before lower seams' mining.

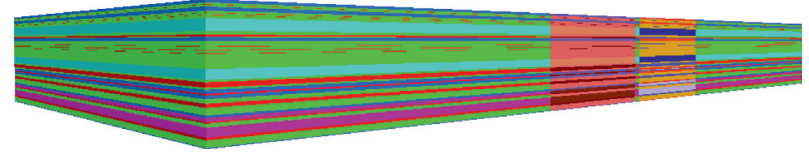

FIGURE 3: Numerical model.

Figures 8 and 9 show that the maximum subsidence of the $1359 \mathrm{P}$ tailgate is about $2.5 \mathrm{~m}$, which is located in the overlapping area of $1378 \mathrm{P}$ gob and $2091 \mathrm{P}$ gob. The maximum subsidence of the $1359 \mathrm{P}$ maingate is about $2.7 \mathrm{~m}$, which is located in the overlapping area of 2071P gob and $2091 \mathrm{P}$ gob. Figure 10 shows the measured and calculated subsidence data of the 1359P roadway floor. The numerical calculation is in good agreement with field measurement.

1.5. Roadway Deformation Monitoring. 3D laser scanning can obtain precise chamber profile data and quick modeling, which has been tested and trialed in deformation monitoring of underground roadway in the coal mine [38-42]. ZEBHORIZON 3D laser scanner is used to analyse the roadway deformation of 1359P. ZEB-HORIZON is a mobile 3D laser scanner based on SLAM algorithm. It can dynamically measure and record 3D spatial information without GPS. Its scanning range is $30 \mathrm{~m}$, the data acquisition rate is 43,200 points/s, the accuracy is $4 \mathrm{~mm} / 100 \mathrm{~m}$, and the angle accuracy is $60 \mathrm{mrad}$. It is the IP64 level that can be used in harsh environment. Its weigh is $3.5 \mathrm{~kg}$ and can be carried personally.

The deformation of roadway can be obtained by multiple scanning. The 3D laser scanning model of the tailgate and maingate of 1359P over 2072P is shown in Figure 11.

Figure 12 shows the outline of the maingate of 1359P, and they are (a) underlying coal mass, (b) over 2072P gob, (c) over pillar between 2072P and 2071P, (d) over 2071P gob, (e) over pillar between 2071P and 1378P, and (f) over 1378P gob. The red and blue lines are two measurements, after roadway development and before 1359 panel excavation, respectively. The calculation results of roof fall and rib convergence are shown in Table 3.

For large deformation of surrounding rock of the roadways, a special ground support scheme should be implemented based on the reinforcement principles and field conditions [43-46]. The maximum roof fall is $30 \mathrm{~mm}$, and the maximum rib convergence is $25 \mathrm{~mm}$. The overall deformation of the roadway is small. At the same time, it was observed that the roof, floor, and ribs of the roadway remained in good condition. Combining with result of theoretical analysis, it can be concluded that the roadway of 1359 panel in \#5 seam is stable, and the panel can be mined as normal. 
TABLE 2: Parameters of coal and rock used in the calculation.

\begin{tabular}{lcccccc}
\hline Rock & $\begin{array}{c}\text { Density } \\
\left(\mathrm{kg} / \mathrm{m}^{3}\right)\end{array}$ & $\begin{array}{c}\text { Tensile } \\
\text { strength }(\mathrm{MPa})\end{array}$ & $\begin{array}{c}\text { Elastic modulus } \\
(\mathrm{MPa})\end{array}$ & $\begin{array}{c}\text { Poisson's } \\
\text { ratio }\end{array}$ & $\begin{array}{c}\text { Cohesion } \\
(\mathrm{MPa})\end{array}$ & $\begin{array}{c}\text { Internal friction } \\
\text { angle }\left(^{\circ}\right)\end{array}$ \\
\hline Siltstone & 2.600 & 1.10 & 15.125 & 0.26 & 1.30 & 34 \\
Coal & 1.323 & 0.28 & 2.173 & 0.28 & 0.28 & 32 \\
Medium & 2.502 & 0.66 & 35.696 & 0.20 & 0.66 & 33 \\
sand & 2.668 & 0.36 & 11.399 & 0.25 & 0.83 & 31 \\
Mudstone & & & & & & \\
\hline
\end{tabular}

Contour of $Y$-displacement

Plane: active on
$1.2164 E+00$
$1.2000 E+00$
$1.1000 E+00$
$1.0000 E+00$
$9.0000 E-01$
$8.0000 E-01$
$7.0000 E-01$
$6.0000 E-01$
$5.0000 E-01$
$4.0000 E-01$
$3.0000 E-01$
$2.0000 E-01$
$1.0000 E-01$
$0.0000 E+01$
$-2.6369 E-03$

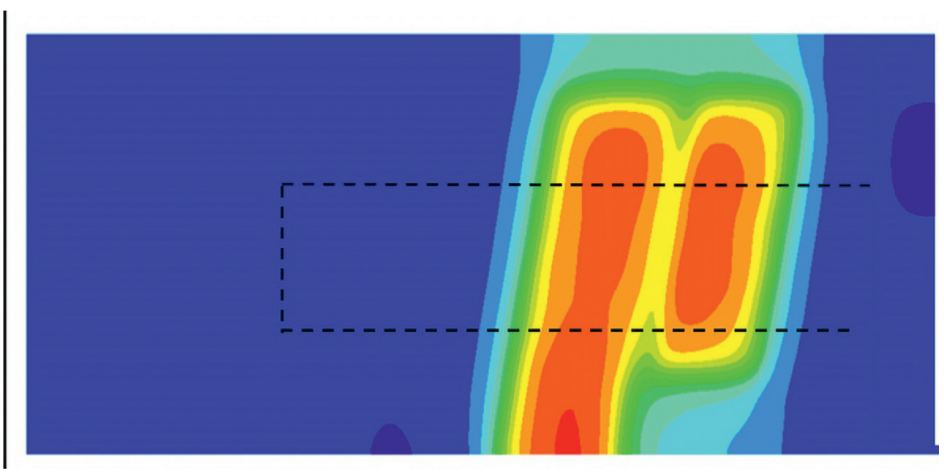

FIGURE 4: Subsidence of \#5 seam floor after $1378 \mathrm{P}$ and $2071 \mathrm{P}$ are mined out.

Contour of $Y$-displacement

Plane: active on

$3.1245 E+00$
$3.0000 E+00$
$2.7500 E+00$
$2.5000 E+00$
$2.2500 E+00$
$2.0000 E+00$
$1.7500 E+00$
$1.5000 E+00$
$1.2500 E+00$
$1.0000 E+00$
$7.5000 E-01$
$5.0000 E-01$
$2.5000 E-01$
$0.0000 E+00$
$-2.5000 E-00$
$-5.0000 E-01$
$-7.3766 E-01$

FIgURE 5: Overlaying strata subsidence of A-A cross section after 2071P is mined out.

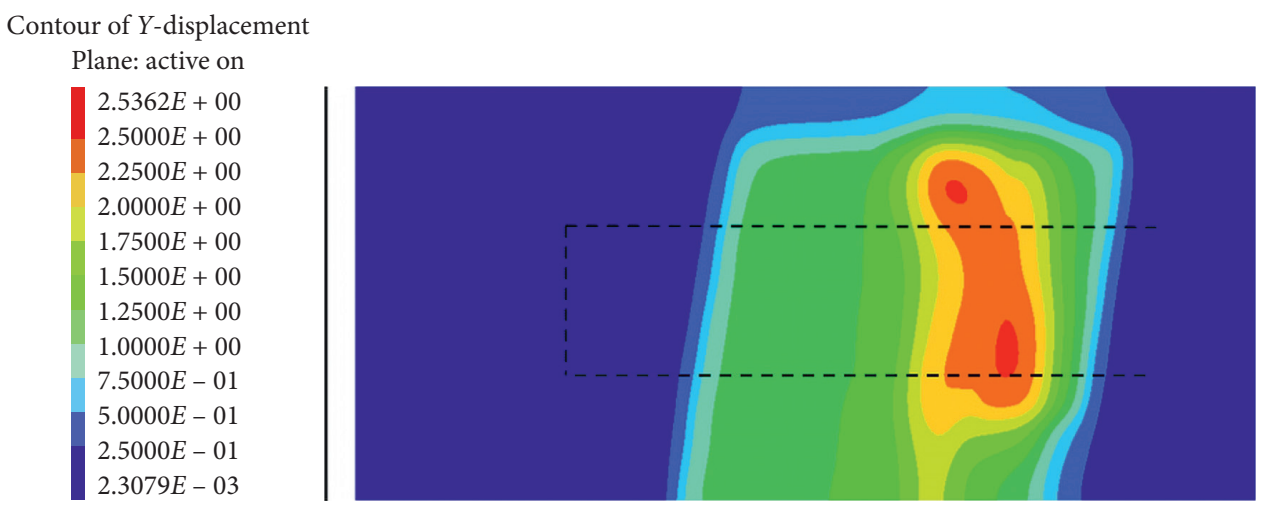

Figure 6: Floor subsidence of $\# 5$ coal seam after lower seam mining. 


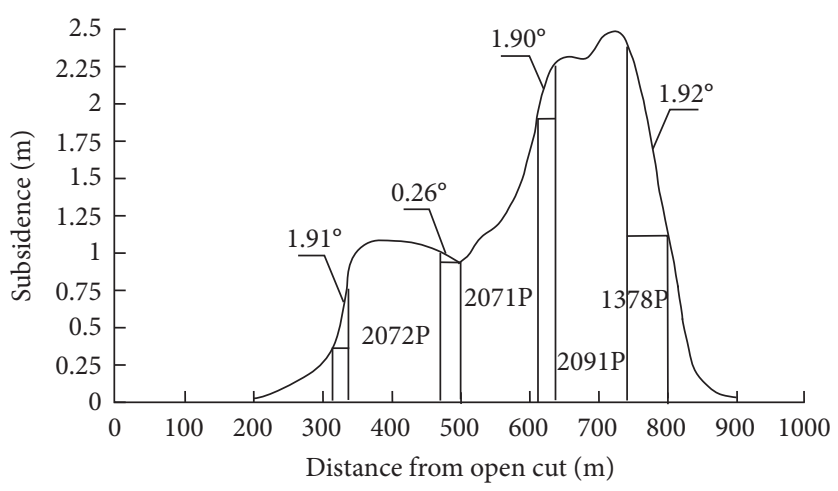

FIgURE 7: Floor subsidence and dipping angles of 1359P after lower seam mining.

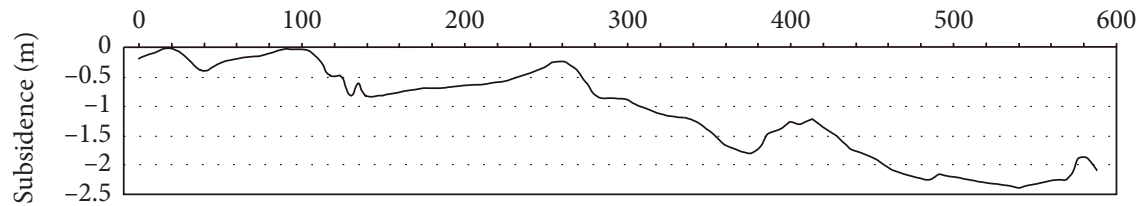

(a)

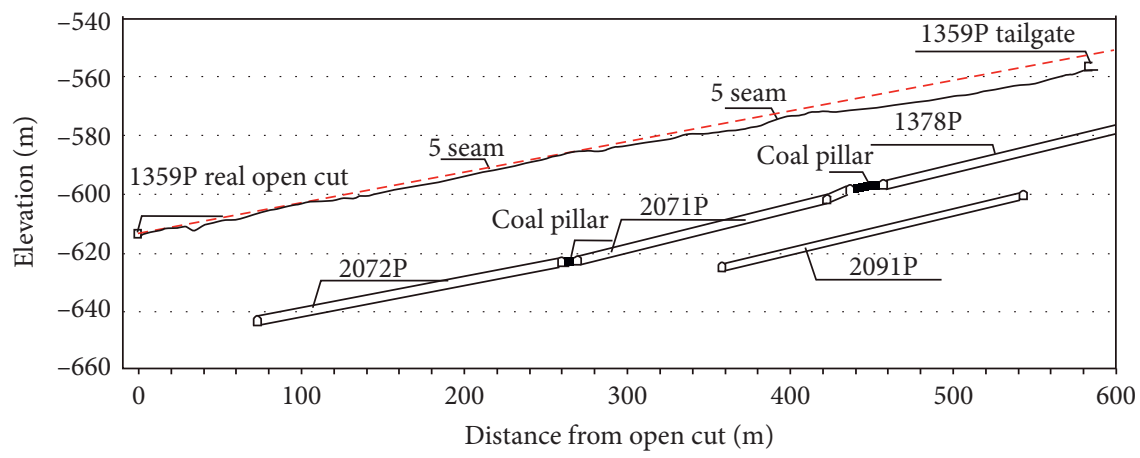

(b)

FIgURE 8: Subsidence of 1359P maingate floor.

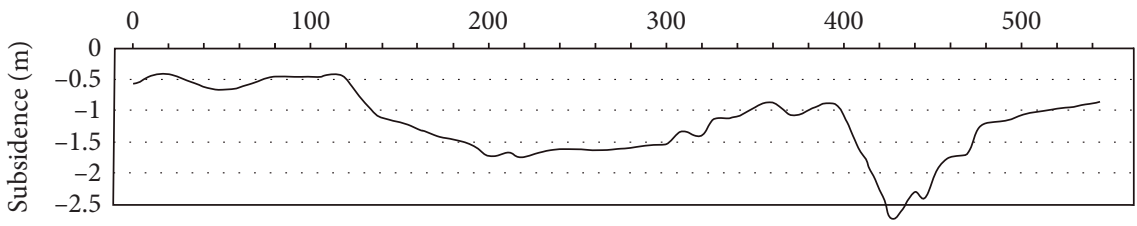

(a)

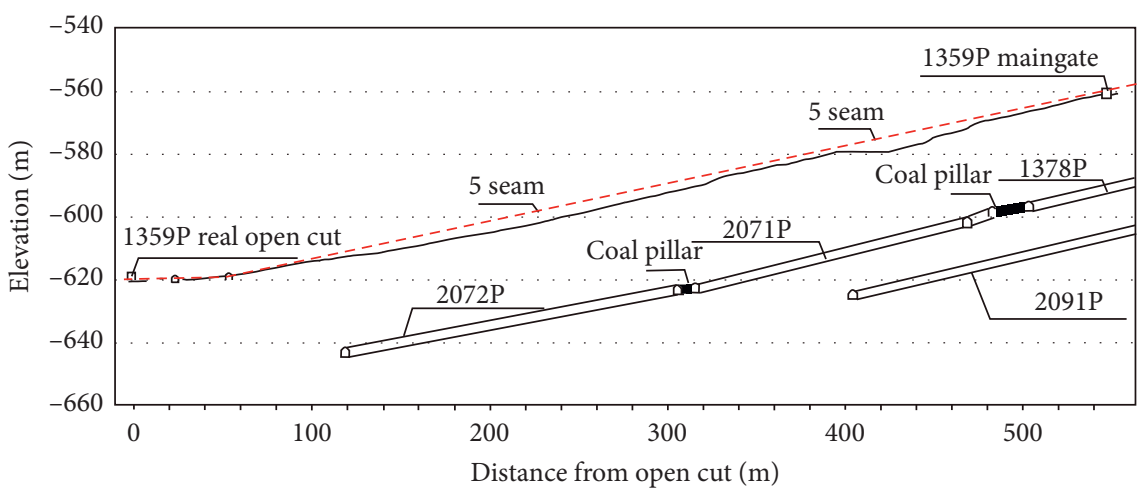

(b)

Figure 9: Subsidence of 1359P tailgate floor. 


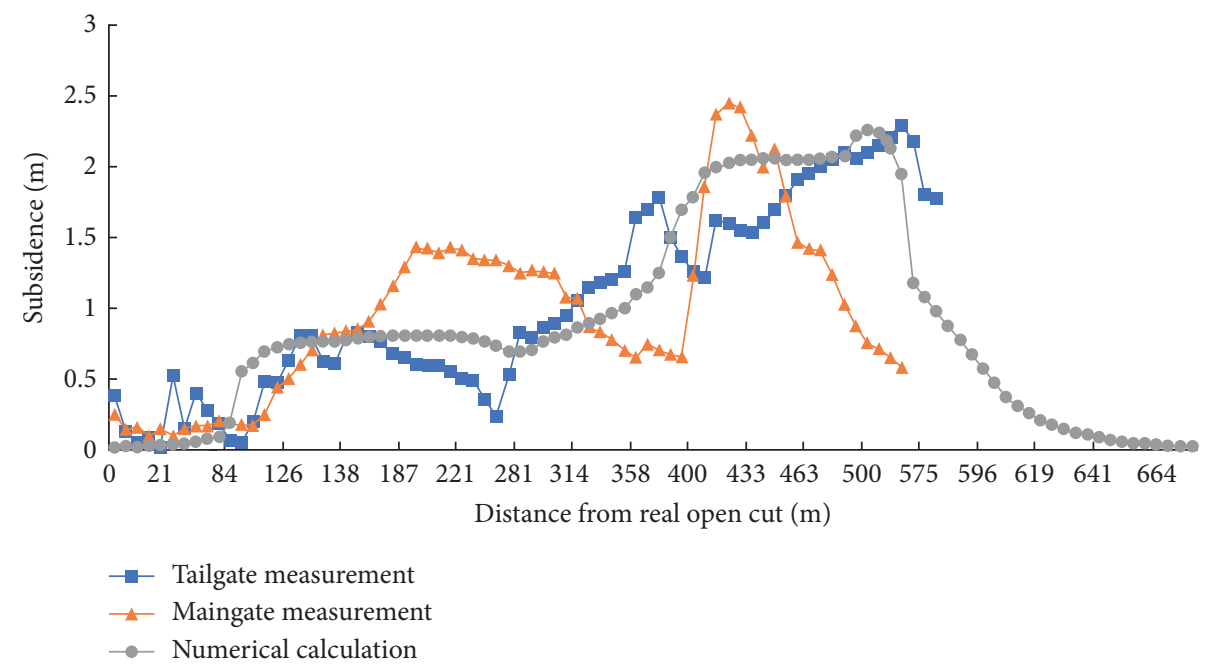

FigurE 10: Comparison of calculated and measured subsidence of 1359P roadway floor.

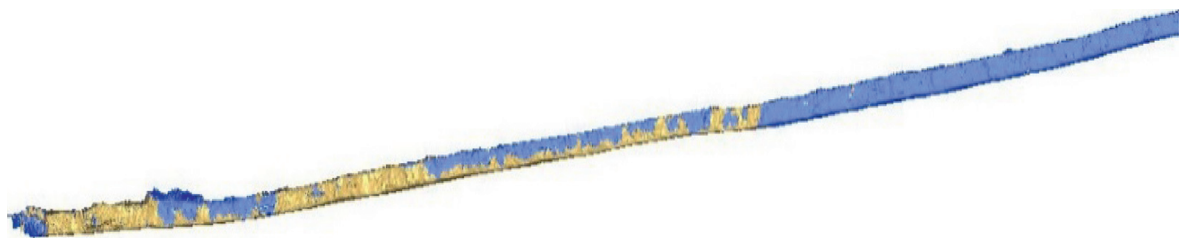

(a)

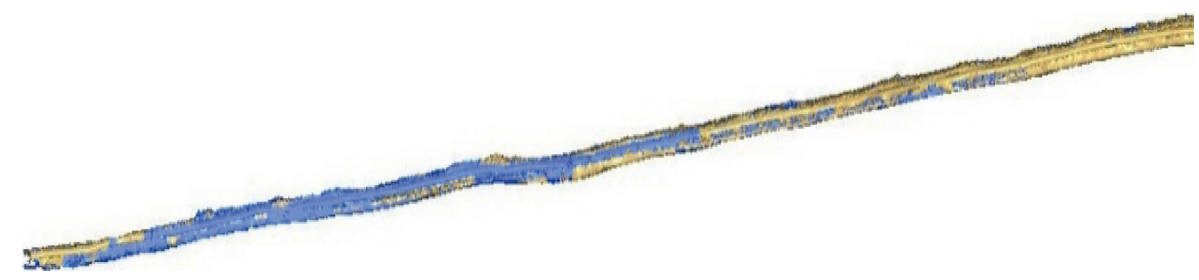

(b)

Figure 11: 3D scanning model of 1359P over 2072P gob: (a) tailgate and (b) maingate.

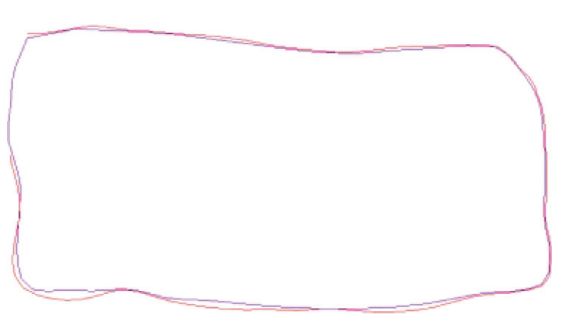

(a)

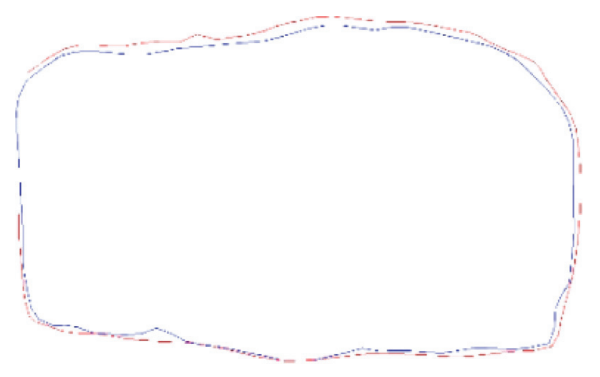

(c)

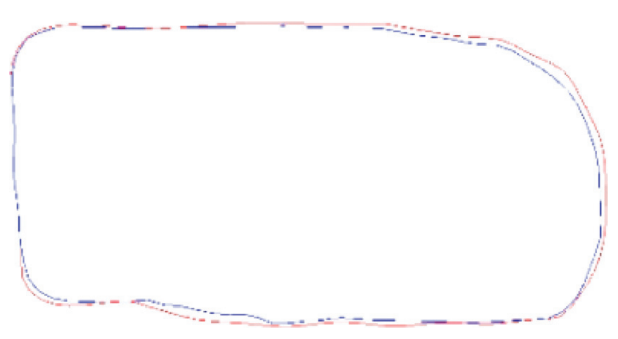

(b)

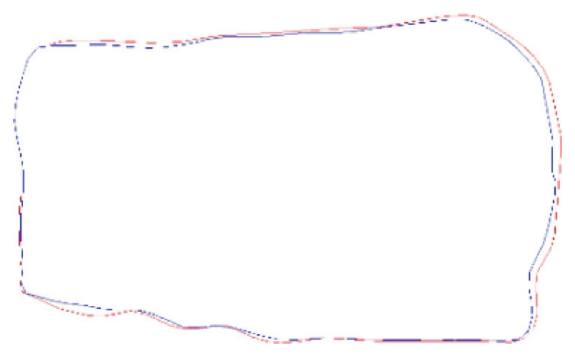

(d)

Figure 12: Continued. 


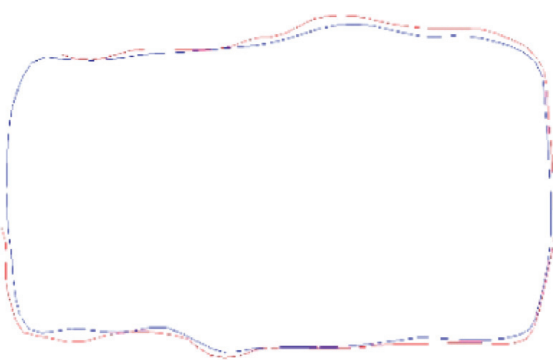

(e)

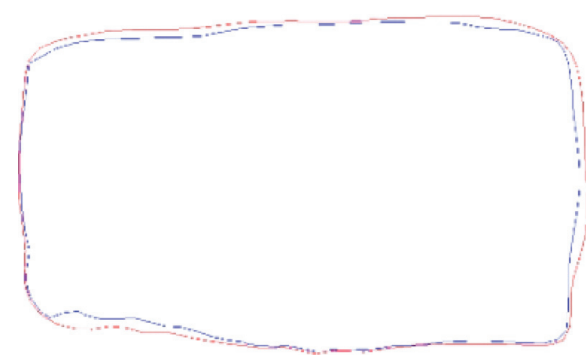

(f)

Figure 12: The profile of 1359P maingate. (a) Underlying coal mass (40 m from open cut). (b) Over 2072P gob (1730 m from open cut). (c) Over pillar between 2072P and 2071P (268 m from open cut). (d) Over 2071P gob (357 m from open cut). (e) Over pillar between $2071 \mathrm{P}$ and $1378 \mathrm{P}$ ( $455 \mathrm{~m}$ from open cut). (f) Over 1378P gob (502 $\mathrm{m}$ from open cut).

TABLE 3: The maximum roadway deformation.

\begin{tabular}{lcccccc}
\hline Distance from open cut $(\mathrm{m})$ & 40 & 173 & 268 & 357 & 455 & 502 \\
\hline Roof fall $(\mathrm{mm})$ & 24 & 20 & 30 & 19 & 29 & 18 \\
Rib convergence $(\mathrm{mm})$ & 12 & 19 & 25 & 17 & 20 & 14 \\
\hline
\end{tabular}

\section{Conclusion}

Based on the upward mining engineering background of the Qianjiaying coal mine, this paper comprehensively uses roof caving analysis and numerical calculation to analyse the mining feasibility of $1350 \mathrm{P}$. In the stage of the roadway development, the roadway subsidence is measured and the roadway deformation is modeled. The following conclusions can be drawn:

(1) The results of caving analysis and numerical calculation show that, under the condition of 2071P. 2091P, 1378P, and 2091P are mined out, and the subsidence of \#5 seam 5 is $1.0-2.5 \mathrm{~m}$. The maximum bending angle of \#5 seam is $1.9^{\circ}$. The subsidence and bending angle results of \#5 seam show that $1359 \mathrm{P}$ roadway can be developed.

(2) Through field measurement, the floor subsidence of $1359 \mathrm{P}$ roadway is obtained. The maximum subsidence of 1359P tailgate is about $2.5 \mathrm{~m}$, located in the overlapping area of $1378 \mathrm{P}$ gob and $2091 \mathrm{P}$ gob. The maximum subsidence of the maingate is about $2.7 \mathrm{~m}$, which is located in the overlapping area of $2071 \mathrm{P}$ gob and 2091P gob. The numerical results are in good agreement with the field measurements.

(3) The roadway deformation is monitored using the multiple $3 \mathrm{D}$ laser scanning method. The maximum roof fall and rib convergence is 30 and $25 \mathrm{~mm}$, respectively. So, $1359 \mathrm{P}$ can be mined as normal.

\section{Data Availability}

All data used to support the findings of the study are included within the article.

\section{Conflicts of Interest}

The authors declare that there are no conflicts of interest regarding the publication of this paper.

\section{References}

[1] J. Han, W. H. Song, and Z. J. Zhu, Overmining Technology of Closed Multi Coal Seams, China Coal Industry Publishing House, Beijing, China, 2013.

[2] L. Zhang, J. H. Li, J. H. Xue et al., "Experimental studies on the changing characteristics of the gas flow capacity on bituminous coal in CO2-ECBM and N2-ECBM," Fuel, vol. 291, Article ID 120115, 2021.

[3] J. Lin, T. Ren, Y. P. Cheng et al., "Cyclic N2 injection for enhanced coal seam gas recovery: a laboratory study," Inside Energy, vol. 188, Article ID 116115, 2019.

[4] J. Lin, T. Ren, G. Wang, P. Booth, and J. Nemcik, "Experimental investigation of $\mathrm{N} 2$ injection to enhance gas drainage in CO2-rich low permeable seam," Fuel, vol. 215, pp. 665-674, 2018.

[5] D. Xue, J. Wang, Y. Zhao, and H. Zhou, "Quantitative determination of mining-induced discontinuous stress drop in coal," International Journal of Rock Mechanics and Mining Sciences, vol. 111, pp. 1-11, 2018.

[6] X. W. Feng, N. Zhang, F. Xue, and Z. Xie, "Practices, experience, and lessons learned based on field observations of support failures in some Chinese coal mines," International Journal of Rock Mechanics and Mining Sciences, vol. 123, Article ID 104097, 2019.

[7] D. J. Xue, J. Zhou, Y. T. Liu et al., "On the excavation-induced stress drop in damaged coal considering a coupled yield and failure criterion," International Journal of Coal Science \& Technology, vol. 7, no. 5, pp. 58-67, 2020.

[8] L. Q. Wang and Z. H. Li, Overmining Technology of Coal Seams, China Coal Industry Publishing House, Beijing, China, 1995.

[9] J. Han, H. W. Zhang, P. T. Zhang et al., "Feasibility study on upward mining in seam group with short distance to each other in Kailuan mining area," Coal Science and Technology, vol. 39, no. 10, pp. 14-17, 2011.

[10] L. Zhang, S. Chen, C. Zhang et al., "The characterization of bituminous coal microstructure and permeability by liquid nitrogen fracturing based on $\mu \mathrm{CT}$ technology," Fuel, vol. 262, Article ID 116635, 2020. 
[11] D. J. Xue, L. L. Lu, J. Zhou et al., "Cluster modeling of the short-range correlation of acoustically emitted scattering signals," International Journal of Coal Science \& Technology, pp. 1-15, 2020.

[12] D. J. Xue, Y. T. Liu, H. W. Zhou, J. Q. Wang, J. F. Liu, and J. Zhou, "Fractal characterization on anisotropy and fractal reconstruction of rough surface of granite under orthogonal shear," Rock Mechanics and Rock Engineering, vol. 53, no. 3, pp. 1225-1242, 2020.

[13] Q. Wang, Z. H. Jiang, B. Jiang et al., "Research on an automatic roadway formation method in deep mining areas by roof cutting with high-strength bolt-grouting," International Journal of Rock Mechanics and Mining Sciences, vol. 128, Article ID 104264, 2020.

[14] D. Cao, A. Wang, S. Ning et al., "Coalfield structure and structural controls on coal in China," International Journal of Coal Science \& Technology, vol. 7, no. 2, pp. 220-239, 2020.

[15] H. Shi, J. Xie, X. Wang, J. Li, and X. Ge, "An operation optimization method of a fully mechanized coal mining face based on semi-physical virtual simulation," International Journal of Coal Science and Technology, vol. 7, no. 1, pp. 147-163, 2020.

[16] C. Wang, N. Zhang, G. C. Li et al., "Control principles for roadway roof stabilization in different zones during ascending mining," Journal of China University of Minim \& Technology, vol. 41, no. 4, pp. 543-550, 2012.

[17] H. W. Zhang, J. Han, L. X. Hai et al., "Study on closed multiple-seam in the ascending mining technology," Journal of Mining \& Safety Engineering, vol. 30, no. 1, pp. 63-67, 2013.

[18] Y. D. Jiang, Y. M. Yang, Z. Q. Ma et al., "Breakage mechanism of roof strata above widespread mined-out area with roadway mining method and feasibility analysis of upward mining," Journal of China Coal Society, vol. 41, no. 4, pp. 801-807, 2016.

[19] A. M. Suchowerska, R. S. Merifield, and J. P. Carter, "Vertical stress changes in multi-seam mining under supercritical longwall panels," International Journal of Rock Mechanics and Mining Sciences, vol. 61, pp. 306-320, 2013.

[20] X. P. Shao, J. T. Wu, J. F. Zhang et al., "Study on crack evolution law of overburden strata and stability of interlayer rock in upward coal mining," Coal Science and Technology, vol. 44, no. 9, pp. 61-66, 2016.

[21] C. Cao, T. Ren, C. Cook, and Y. Cao, "Analytical approach in optimising selection of rebar bolts in preventing rock bolting failure," International Journal of Rock Mechanics and Mining Sciences, vol. 72, pp. 16-25, 2014.

[22] Q. Wang, Y. Wang, M. C. He et al., "Experimental research and application of automatically formed roadway without advance tunneling," Tunnelling and Underground Space Technology, vol. 114, no. 3, Article ID 103999, 2021.

[23] C. Cao, T. Ren, and C. Chris, "Introducing aggregate into grouting material and its influence on load transfer of the rock bolting system," International Journal of Mining Science and Technology, vol. 24, no. 3, pp. 325-328, 2014.

[24] W. P. Huang, W. B. Xing, Y. S. Zheng et al., "Reasonable layout of roadways for upward mining technology of close coal seams," Chinese Journal of Rock Mechanics and Engineering, vol. 36, no. 12, pp. 3028-3039, 2017.

[25] C. L. Zhang, "Study on overlying strata caving and movement regularity of ascending mining in contiguous seams," Coal Science and Technology, vol. 46, no. 8, pp. 1-7, 2018.

[26] X. Z. Zhao, Z. Y. Gao, T. Wu et al., "Study on roadway layout of the ascending mining panels in closed distance coal seams," Chinese Journal of Underground Space and Engineering, vol. 15, no. 1, pp. 194-201, 2019.
[27] Y. Wang, X. Y. Fu, L. H. Kong et al., "Study on the stability of dangling structure in ascending mining close distance coal seams," Coal Science and Technology, vol. 48, no. 12, pp. 95-100, 2020.

[28] "State Administration of safety supervision, State Administration of coal mine safety, National Energy Administration, State Railway Administration," Code for Coal Pillar Setting and Coal Pressure Mining in Buildings, Water Bodies, Railways and Main Roadways, http://www.mem.gov.cn/gk/gwgg/ 201707/t20170703_241729.shtml, 2017.

[29] Z. Bi, J. Han, B. Liang, B. Huo, C. Cao, and S. Ma, “Analysis of strata stress and its effect on lower-level seam exploitation under room-and-pillar shallow coal mining," Journal of Engineering Science and Technology Review, vol. 14, no. 1, pp. 79-85, 2021.

[30] S. R. Wang, X. G. Wu, Y. H. Zhao et al., "Evolution characteristics of composite pressure-arch in thin bedrock of overlying strata during shallow coal mining," International journal of applied mechanics, vol. 11, no. 3, Article ID 1950030, 2019.

[31] J. Han, H. Liang, C. Cao, Z. Bi, and Z. Zhu, "A mechanical model for sheared joints based on Mohr-Coulomb material properties," Géotechnique Letters, vol. 8, no. 2, pp. 92-96, 2018.

[32] P. Luo, S. Wang, P. Hagan et al., "Mechanical performances of cement-gypsum composite material containing a weak interlayer with different angles," Dyna, vol. 94, no. 4, pp. 447-454, 2019.

[33] C. Zhu, M. C. He, M. Karakus, X. H. Zhang, and Z. Guo, "The collision experiment between rolling stones of different shapes and protective cushion in open-pit mines," Journal of Mountain Science, vol. 18, no. 5, pp. 1391-1403, 2021.

[34] C. Zhu, M. He, M. Karakus, X. Zhang, and Z. Tao, "Numerical simulations of the failure process of anaclinal slope physical model and control mechanism of negative Poisson's ratio cable," Bulletin of Engineering Geology and the Environment, vol. 80, no. 4, pp. 3365-3380, 2021.

[35] D. Xue, H. Zhou, Y. Zhao, L. Zhang, L. Deng, and X. Wang, "Real-time SEM observation of mesoscale failures under thermal-mechanical coupling sequences in granite," International Journal of Rock Mechanics and Mining Sciences, vol. 112, pp. 35-46, 2018.

[36] X. Lian, H. Hu, T. Li, and D. Hu, "Main geological and mining factors affecting ground cracks induced by underground coal mining in Shanxi Province, China," International Journal of Coal Science and Technology, vol. 7, no. 2, pp. 362-370, 2020.

[37] B. Chen, "Stress-induced trend: the clustering feature of coal mine disasters and earthquakes in China," International Journal of Coal Science \& Technology, vol. 7, no. 4, pp. 676692, 2020.

[38] V. Kajzar, R. Kukutsch, P. Waclawik, and J. Nemcik, "Innovative approach to monitoring coal pillar deformation and roof movement using 3D laser technology," Procedia Engineering, vol. 191, pp. 873-879, 2017.

[39] X. Y. Liu, Q. S. Hu, and H. J. Li, "Research on coal mine roof monitoring based on three-dimensional laser scanning technology," China Coal, vol. 43, no. 7, pp. 81-83, 2017.

[40] L. L. Guo, D. W. Zhou, D. M. Zhang et al., "Deformation and failure law of surrounding rock of roadway of mining action," Journal of Mining and Strata Control Engineering, vol. 3, no. 2, Article ID 023038, 2021.

[41] D. J. Xue, H. W. Zhou, Y. T. Liu, L. S. Deng, and L. Zhang, "Study of drainage and percolation of nitrogen-water flooding 
in tight coal by NMR imaging," Rock Mechanics and Rock Engineering, vol. 51, no. 11, pp. 3421-3437, 2018.

[42] S. Mao, "Development of coal geological information technologies in China," International Journal of Coal Science \& Technology, vol. 7, no. 2, pp. 320-328, 2020.

[43] X. Feng, N. Zhang, S. Yang, and F. He, "Mechanical response of fully bonded bolts under cyclic load," International Journal of Rock Mechanics and Mining Sciences, vol. 109, pp. 138-154, 2018.

[44] J. Han, S. Wang, Y. Chen, and C. Cao, "Analytical derivation of rib bearing angle of reinforcing bar subject to axial loading," Magazine of Concrete Research, vol. 71, no. 4, pp. 175-183, 2019.

[45] C. Cao, T. Ren, and C. Cook, "Calculation of the effect of Poisson's ratio in laboratory push and pull testing of resinencapsulated bolts," International Journal of Rock Mechanics and Mining Sciences, vol. 64, pp. 175-180, 2013.

[46] X. W. Feng, N. Zhang, Z. J. Wen et al., "Mechanical responses and acoustic emission properties of bolting system under short encapsulation cyclic thrust tests," International Journal of Fatigue, vol. 121, pp. 39-54, 2018. 